\title{
Being Indexed in SCIE: A Major Step Forward for Endocrinology and Metabolism
}

\author{
Won-Young Lee \\ Editor-in-Chief of Endocrinology and Metabolism
}

We received the excellent news from Clarivate Analytics that Endocrinology and Metabolism (EnM, https://www.e-enm.org), which is the official journal of the Korean Endocrine Society (http://www.endocrinology.or.kr), was indexed in the Science Citation Index Expanded (SCIE) in August 2019. I am very pleased to share this information with the readers, reviewers, and editors of EnM. Clarivate Analytics informed me on August 16, 2019 that EnM (beginning with the 2017 volume) has been accepted for inclusion in SCIE. This is a great step forward for EnM on its journey to become a world-renowned journal in the field of endocrinology and metabolism.

We, the editors of EnM, have devoted ourselves to make EnM a SCIE journal with the goal of establishing it as an excellent platform for the communication of the newest scientific knowledge in the field of endocrinology. We have worked diligently for the content of EnM to consist of the highest-quality papers. Many excellent review papers and original articles have been published in EnM and cited. We have strengthened our ethical policies to adhere with all ethical guidelines suggested by the International Committee of Medical Journal Editors (ICMJE) and Guidelines on Good Publication (Committee on Publication Ethics [COPE]). Close examinations have been performed of all articles before publication by statistical editors, manuscript editors, and a professional English editing company (Compecs Inc., Seoul, Korea), enabling us to maintain a high-quality system. Editorial policies and best practices on the EnM homepage have been actively implemented and firmly maintained. High-

Received: 22 August 2019, Accepted: 28 August 2019

Corresponding author: Won-Young Lee

Division of Endocrinology and Metabolism, Department of Internal Medicine, Kangbuk Samsung Hospital, Sungkyunkwan University School of Medicine, 29 Saemunan-ro, Jongno-gu, Seoul 03181, Korea

Tel: +82-2-2001-2579, Fax: +82-2-2001-2049, E-mail: drlwy@hanmail.net quality papers, such as meta-analyses and randomized controlled trials, are being published in EnM with increasing frequency.

The first issue of the journal was published at 1986 by the Korean Endocrine Society, and its scope has subsequently been widened to include authors from throughout the world. In the most recent 5 years, articles by authors from 32 countries on six continents have been published in EnM, and it has experienced a steep increase in its self-calculated impact factor from the Web of Science Core Collection, which was 2.1 in 2016, 2.9 in 2017, and 2.8 in 2018. We have also many excellent scientists as editorial board members, which is a major source of pride for me. They are major researchers who publish their works in top journals such as Nature and NEJM as principal investigators, and many of them are editors-in-chief of major endocrine journals.

EnM has been indexed in KoreaMed, KCI, PubMed, PubMed Central, EBSCO, DOAJ, EMBASE, CAS, SCOPUS, Google Scholar, and ScienceCentral (http://e-sciencecentral.org). which provides free full-text archives of scientific journals published by members of the Korean Federation of Science and Technology Societies with translations into 80 other languages in collaboration with Google Translate. It was a great honor to me for EnM to be indexed in MEDLINE in March 2019 [1].

We recently published our triennial report, giving more details on the improvements that EnM has made [2]. To make EnM a more readable journal, we have implemented audio summaries to introduce the contents of each issue and audio slides

Copyright $\odot 2019$ Korean Endocrine Society

This is an Open Access article distributed under the terms of the Creative Commons Attribution Non-Commercial License (http://creativecommons.org/ licenses/by-nc/4.0/) which permits unrestricted non-commercial use, distribution, and reproduction in any medium, provided the original work is properly cited. 
of the articles made by the authors. I think that this is a trendy and elegant service to cope with the rapidly changing environment of scientific research. I am very grateful for these improvements and I would like to express my sincere appreciation for the diligent efforts of our editorial team. In particular, Prof. Eun-Jung Rhee has passionately devoted herself to the journal as a deputy editor and Hye Yeon Jang, a manuscript editor, has also shown tremendous dedication to the mission of the journal. All of our editors have also made major contributions to the success of EnM, and their sincere efforts have allowed our journal to become one of the major journals in the field of endocrinology. I hope that EnM will continue to improve as a global platform to present investigators' high-quality scientific findings in the field of endocrinology.

Lastly, I would like to express my sincere gratitude to the readers, reviewers, all the editorial board members of EnM, all members of the Korean Endocrine Society, and all international contributors. I firmly believe that EnM will continue to progress further and once more express my gratitude to all.

\section{CONFLICTS OF INTEREST}

No potential conflict of interest relevant to this article was reported.

\section{ORCID}

Won-Young Lee https://orcid.org/0000-0002-1082-7592

\section{REFERENCES}

1. Lee WY. Endocrinology and Metabolism has been indexed in MEDLINE: a major achievement. Endocrinol Metab (Seoul) 2019:34:138-9.

2. Rhee EJ, Jang HY, Lee WY. Triennial report of Endocrinology and Metabolism, 2015 to 2017. Endocrinol Metab (Seoul) 2018;33:195-201. 